\title{
Sedentarism, A Modifiable Risk Factor for Developing Chronic Kidney Disease in Healthy People
}

\author{
Alejandro Tavera Concha ${ }^{1,2, *}$, Franklin Alejandro Rico Mendoza ${ }^{3,4}$ \\ 'Physician with an emphasis on Family Medicine, La Sabana University, Chia, Colombia \\ ${ }^{2}$ Postgraduate student in Epidemiology at El Bosque University, Bogota, Colombia \\ ${ }^{3}$ Epidemiologist M.Sc. Coordinator of the Master's Degree in Epidemiology at El Bosque University, Bogota, Colombia \\ ${ }^{4}$ University of Cundinamarca, Zootechnics, National Open and Distance University, Bogota, Colombia
}

\section{See editorial commentary page on 1}

Background: Chronic kidney disease (CKD) is a consequence of the interaction of many pathophysiological processes, manifested by a decrease in the glomerular filtration rate (GFR) and abnormal kidney function. Sedentary behavior is associated with decreased kidney function, and regular physical activity could have the potential to reduce the risk of developing CKD, although this is not entirely clear. The objective of this study was to investigate the relationship between sedentary behavior and the development of CKD.

Methods: A search was carried out in different databases and metasearchers from January 2015 to June 2020 for cross-sectional, case-control, and cohort studies, in which the association of a sedentary lifestyle or physical inactivity with the appearance of CKD was evaluated in healthy people. Eight articles were obtained, including six crosssectional studies, one case-control, and one cohort study. The quality of evidence for the main outcomes was assessed using the GRADE (Grading of Recommendations, Assessment, Development, and Evaluation) model.

Results: Most of the studies included in this systematic review agree that there is an association between a sedentary lifestyle and CKD; however, not all used the same definition of this disease, in the same way, the definitions of physical activity and sedentary behavior were different between these studies, as well as the methods of measuring sedentary behavior.

Conclusion: CKD could be associated with sedentary behavior in previously healthy people. It was not possible to determine a measure of association with the available scientific evidence, as the study designs were heterogeneous. Modifiable risk factors should be considered in different population groups to reduce the risk of CKD.

Keywords: Sedentary Behavior; Chronic Kidney Failure; Chronic Renal Insufficiency; Case-Control Studies; Epidemiologic Studies; Cohort Studies; Cross-Sectional Studies 


\section{INTRODUCTION}

Chronic kidney disease (CKD) is a consequence of the interaction of many pathophysiological processes, which can lead to a decrease in the glomerular filtration rate (GFR) by $<60 \mathrm{~mL} / \mathrm{min}$ per body surface $\left(1.73 \mathrm{~m}^{2}\right)$, and abnormal kidney function, which is present in approximately $10 \%$ of the population worldwide, as reported by the Latin American Society of Nephrology and Hypertension (SLANH in Spanish) and the World Health Organization. ${ }^{\text {) }}$

The prevalence of CKD has increased in recent years. Approximately 500 million people are estimated to suffer from this disease worldwide, ${ }^{2)}$ representing a significant burden of disease. ${ }^{3)}$ Furthermore, CKD is also a risk factor for triggering CKD in more advanced and terminal stages, as well as for cardiovascular disease (CVD); thus generating more premature deaths. ${ }^{4)}$ According to information from the 2013 Global Burden of Disease study, mortality from CKD increased by $36.9 \%$ between 1990 and 2013. ${ }^{5)}$

In Colombia, according to the High-Cost Account (CAC in Spanish), it was estimated that the prevalence of CKD for the period from July 1 , 2017 to June 30, 2018 was 1,479,733 cases, with an age-adjusted rate of 2.9 cases per 100 inhabitants, in which $61.4 \%$ were women, and an incidence of 247,122 new cases, with an age-adjusted rate of five cases per 1,000 inhabitants for the same period, with an average age of 61.6, in which $61.2 \%$ were women. ${ }^{6}$

CKD has become a pathology of interest in public health at a global level, which is why it is considered a high cost for the general system of social security in health (SGSSS in Spanish) in Colombia, since it has a strong economic impact, significantly altering the finances of the system, in addition to compromising the quality of life of the patient and the family. ${ }^{7)}$

Physical activity involves body movement produced by the contraction of the skeletal muscles, which substantially increases energy expenditure. These activities can vary according to type, intensity, and duration. In addition, physical activity can also refer to intentional efforts to improve metabolic and physical function, other routine, or sporadic calorie-spending behaviors, such as commuting, occupational tasks, or recreational activities. Exercise is considered a subset of physical activity that is structured with the intention of developing physical fitness, such as improvements in cardiovascular function, strength, and flexibility. Alternatively, sedentary behaviors, or lack of physical activity above resting metabolic rate, are themselves emerging as important independent variables when assessing metabolic and cardiovascular risk. ${ }^{8)}$ Therefore, reducing periods of sitting, lying down, watching television, computers, and video games has become a potential goal for improving health. ${ }^{\text {9) }}$

Physical activity has been shown to be effective in improving cardiovascular endothelial function in patients with CVD. ${ }^{10)}$ Therefore, it might be expected that the kidney vasculature will also experience similar benefits, leading to protection against filtration barrier defects, albuminuria, and impaired kidney function. Physical activity improves vascular insulin signaling, increases bioavailable nitric oxide (NO), and reduces reactive oxygen species (ROS). At the molecular level, physical activity restores NO production by increasing L-arginine availability from the NO precursor molecule and endothelial NO synthase activity and reducing NO degradation by decreasing ROS. ${ }^{11)}$ Furthermore, by reducing angiotensin II and other inflammatory molecules, such as tumor necrosis factor- $\alpha$, exercise improves endothelial responses to insulin. In fact, inflammation, insulin resistance, oxidative stress, and an overactive renin-angiotensin system mutually perpetuate each other while negatively affecting endothelial function, vascular integrity, and ultimately, cardiovascular health. ${ }^{9)}$

Traditional therapeutic lifestyle goals for the treatment and prevention of obesity and chronic diseases have focused on increased moderate-to-vigorous-intensity physical activity (MVPA) and a healthy diet. Increasing evidence suggests that time spent in sedentary behavior, commonly defined as all non-exercise sitting/lying activities performed during waking hours, is associated with increased adiposity, ${ }^{12)}$ metabolic syndrome, ${ }^{13)}$ abnormal glucose regulation, ${ }^{14)}$ and mortality ${ }^{15-17)}$ independent of MVPA. However, there has been limited research investigating the possible mechanisms underlying these observations. Hormones released by the adipose tissue, which are collectively called adipokines, particularly those centrally involved in or linked to the inflammatory cascade, such as interleukin- 6 and adiponectin, are believed to be directly involved in the pathogenesis of many chronic diseases. ${ }^{18,19)}$

Leptin, another well-characterized adipokine, plays a central role in energy homeostasis and is believed to be a key modulator of the inflammatory response. ${ }^{20)}$ Inflammatory adipokines and leptin have previously been inversely associated with MVPA; ${ }^{21-24)}$ however, it is currently unknown whether total sedentary time is strongly associated with adipokine levels. ${ }^{25}$

According to Beddhu, ${ }^{26)}$ in order to reduce high mortality in the CKD population, it is necessary to address the "non-kidney" problems that contribute to increased morbidity and mortality in this population. In a study on the relevance of sedentary behavior in CKD, prolonged sitting time, assessed using a questionnaire or television viewing time, was associated with lower kidney function. Total and light physical activities, measured objectively with an accelerometer, were found to be positively associated with kidney function in a study of adults living in communities. An analysis of data from the National Health and Nutrition Examination Survey found that participants with CKD spent more than two-thirds of their waking time on sedentary activities, and the longest duration sedentary lifestyle was associated with increased mortality. ${ }^{26)}$

According to Beddhu, ${ }^{26)}$ non-exercise activity thermogenesis (NEAT) and the biological importance of low-intensity activity, in a study of overfeeding, showed that the increase, average of $336 \mathrm{kcal} / \mathrm{d}$, in the NEAT accounted for 10 -fold differences in fat storage, directly predicting resistance to fat gain, and explained most of the variations in weight gain among participants. Patients with obesity have less NEAT and spend an average of 2 hours per day in a sitting position compared to thin people. ${ }^{26)}$ 
Participation in regular physical activity has the potential to reduce the risk of developing various chronic diseases. ${ }^{27)}$ Furthermore, physical activity confers various biological benefits that could counteract the adverse metabolic environment of CKD. A previous study showed that greater amounts of physical activity during leisure time was associated with lower rates of decreased kidney function in a large community-based cohort study. ${ }^{28)}$

Knowing the burden of the disease attributed to CKD, as well as the impact that it generates when considered as high cost, it is necessary to identify the association between sedentary lifestyle or physical inactivity with the development of CKD, which could enhance prevention campaigns at the national and international levels.

This study sought to define whether there is a relationship between sedentary lifestyle and the development of CKD. Specifically, the review points to: (1) Describe the sedentary behavior in different age groups. (2) Analyze the described risk and its variations in sedentary patients with CKD. (3) Analyze the existing associations between sedentary behavior and CKD through a meta-analysis, based on the studies found.

\section{METHODS}

This is a systematic review of the literature, wherein a search was carried out using the "PROSPERO (International Prospective Register of Systematic Reviews)" tool of the National Health Service, ${ }^{29)}$ with the aim of determining whether there are already similar works in the same scientific field, without finding any related work. The registration number assigned in PROSPERO was 207783.

Subsequently, we searched for articles that were related to the topic of interest using the PRISMA (Preferred Reporting Items for Systematic reviews and Meta-Analyses) reporting guides for systematic reviews, ${ }^{30}$ the search was carried out between January 2015 and June 2020, in the PubMed metasearch engine, Elsevier's Exerpta Medica database (EMBASE), TRIP Database, Cochrane Library, ScienceDirect, LILACS-Bireme database, and Open Gray Database, using the following medical subject headings (MeSH) terms: sedentary behavior; kidney failure, chronic; chronic kidney disease; case-control studies; epidemiologic studies; cohort studies; and cross-sectional studies.

Related articles (in snowball) were also searched, and the rest of the bibliographic references were obtained. The articles obtained were downloaded to discard those that were not relevant to the work according to the title and abstract, the total of the remaining articles were read and critically analyzed to determine whether the articles could be considered as bibliographic material to answer the questions of the present study.

For the statistical analysis and table composition of this systematic review Manager (RevMan) ver. 5.3 software (Cochrane, London, UK) was used.

\section{Population}

During the review, the following inclusion criteria were considered.
Considering that this is a subject that has not been investigated in a large number of studies, and that the scientific evidence is limited, this study considered people of all ages and of both sexes, who did not have a known diagnosis of CKD as a base pathology or with a GFR of $>60 \mathrm{~mL} / \mathrm{min}$ per $1.73 \mathrm{~m}^{2}$; however, most studies focus on sedentary lifestyle and worsening CKD that lead to a rapid progression towards other stages, overall, in patients who are undergoing hemodialysis or peritoneal dialysis.

\section{Intervention}

We considered studies that included people who had sedentary lifestyles and evaluated physical activity by different methods, among which, one was a standardized questionnaire administered by the interviewer, derived from the Leisure Time Physical Activity Questionnaire, ${ }^{31)}$ complemented by lower intensity activities that were usually carried out by older adults. ${ }^{32)}$ Participants had reported the amount of time they spent doing domestic and care activities (housework, grocery shopping, and laundry), exercise (aerobic dance and weight training), and walking (walking for exercise, walking and climbing stairs) per week.

\section{Comparator}

The comparators were people who regularly engaged in physical activity, which can be measured according to different questionnaires, such as the Rapid Assessment of Physical Activity. ${ }^{33)}$ The duration and intensity of weekly physical activity can be converted into hourly/weekly metabolic equivalents, based on the Ainsworth's compendium of physical activities, ${ }^{34)}$ which can help classify the intensity of physical activity; however, there are other methods to define a physical activity, as stated by each study separately, since not all studies use it.

\section{Results}

The outcome sought was the development of CKD as a consequence of physical inactivity or sedentary lifestyle and not as another associated cause, considering that alterations in kidney function were determined according to the GFR of $<60 \mathrm{~mL} / \mathrm{min}$ for $1.73 \mathrm{~m}^{2}$.

\section{1) Context}

This study considered all studies conducted worldwide in healthcare settings (hospitals, clinics, or health centers).

\section{2) Types of studies}

This study considered all possible studies between case-control studies, cohort studies, and cross-sectional studies, as well as scientific evidence related to the topic of interest.

\section{3) Search strategy}

The search strategy aimed to find published and unpublished studies in Spanish and English. A three-step search strategy was used in this study. A limited initial search was performed on metasearch engines such as PubMed, EMBASE, TRIP Database, Cochrane Library, Scien- 
ceDirect, LILACS-Bireme Database, and OpenGray Database, and then examined whether keywords were within the article, as well as the summary and index terms used to describe the article. Subsequently, a second search was performed with all identified keywords and terms of the index in all the databases included. Finally, we searched for additional studies in the reference list of all identified snowball reports and articles. Published and unpublished articles were recorded without restrictions on the age of the participants and country.

\section{4) Selection of studies}

Following the search procedure above, all identified citations were uploaded to EndNote (Clarivate Analytics, Philadelphia, PA, USA) and duplicates were removed. Titles and abstracts were examined by two independent reviewers to evaluate the inclusion criteria for the review. The full texts of potentially eligible studies were retrieved and assessed in detail by two independent reviewers according to the inclusion criteria.

\section{5) Assessment of methodological quality}

Two individuals (T.A. and R.A. [non-author]) independently assessed the quality of eligible studies prior to inclusion in the review using assessment tools from the Joanna Briggs Institute (JBI) for experimental, quasi-experimental, and other comparative study designs. ${ }^{35,36)}$ After evaluation, studies that did not meet the methodological criteria were excluded. All disagreements between the reviewers were resolved by discussion, and a third reviewer was not required.

\section{6) Data extraction and synthesis}

Quantitative data were extracted from articles included in the review using the JBI standardized data extraction tool. ${ }^{37)}$ Relevant information was extracted, such as the characteristics of the population, year of publication, authors, type of intervention, and summary of the findings. Lead authors would be asked to provide additional information on articles, if needed, but this situation did not arise. Details of data from primary studies with limited data or with limited follow-up were verified by request to authors and by verification of subsequent publications from the same project, based on cross-checking of linked publications from trial registries and if trial registration number exists.

Measures of effect reported in the form of mean difference and standard deviation for continuous variables, and relative risk, odds ratio (OR), and confidence interval (CI) for dichotomous variables were extracted and reported. Since the studies were methodologically or clinically heterogeneous, statistical pooling was not possible; therefore, the results were presented as a systematic review. The quality of the evidence for the main results reported in each study was assessed using a software package based on the GRADE (Grading of Recommendations, Assessment, Development, and Evaluation) model. ${ }^{38)}$

\section{RESULTS}

The study returned 265 records. After selecting titles and abstracts, 65 records were retained for critical reading and full-text evaluation. Twenty records were included for critical appraisal according to predefined inclusion criteria. Finally, eight studies were included (Appen$\operatorname{dix} 1)$.

\section{Description of the Characteristics of the Included Studies}

The eight studies included in this study were conducted in the United States (Hawkins et al. ${ }^{39}$ ) in 2015, Pharr et al. ${ }^{40)}$ in 2018, Lee et al. ${ }^{41)}$ in

Table 1. Characteristics of the studies

\begin{tabular}{|c|c|c|c|c|c|c|}
\hline Study ID & Country & Study types & No. of participants & Exposition/intervention & Comparison & Outcomes \\
\hline $\begin{array}{l}\text { Hawkins et al. }{ }^{39)} \\
(2015)\end{array}$ & USA & Cohort study & 2,435 older adults & $\mathrm{TV}:<2 \mathrm{~h} / \mathrm{d}, 2-3 \mathrm{~h} / \mathrm{d},>3 \mathrm{~h} / \mathrm{d}$ & $\begin{array}{l}\text { Physical activity: 0-48 kcal/ } \\
\text { kg/wk, 48-93 kcal/kg/wk, } \\
>93 \text { kcal/kg/wk }\end{array}$ & $\begin{array}{l}\text { Chronic kidney failure: GFR } \\
<60 \mathrm{~mL} / \mathrm{min} / 1.73 \mathrm{~m}^{2}\end{array}$ \\
\hline $\begin{array}{l}\text { Su et al. }{ }^{42)} \\
(2015)\end{array}$ & Taiwan & $\begin{array}{l}\text { Case-control } \\
\text { study }\end{array}$ & $\begin{array}{l}10,463 \text { (5,328 cases and } \\
5,135 \text { controls) }\end{array}$ & $\begin{array}{l}\text { Sedentary lifestyle among } \\
\text { other risk factors }\end{array}$ & Physical activity & $\begin{array}{l}\text { Exercise habits in chronic } \\
\text { kidney disease }\end{array}$ \\
\hline $\begin{array}{l}\text { Lee et al. }{ }^{43)} \\
(2016)\end{array}$ & Japan & $\begin{array}{l}\text { Cross-sectional } \\
\text { study }\end{array}$ & $\begin{array}{l}10,242 \text { older adults ( } 5,002 \\
\text { men, 5,240 women) }\end{array}$ & $\begin{array}{l}\text { Sitting: }<4 \mathrm{~h} / \mathrm{d}, 4-<6 \mathrm{~h} / \mathrm{d}, \\
6-<8 \mathrm{~h} / \mathrm{d}, \geq 8 \mathrm{~h} / \mathrm{d}\end{array}$ & Physical activity & $\begin{array}{l}\text { Sedentary time, impaired } \\
\text { kidney function }\end{array}$ \\
\hline $\begin{array}{l}\text { Parsons et al. }{ }^{44)} \\
\quad(2017)\end{array}$ & England & $\begin{array}{l}\text { Cross-sectional } \\
\text { study }\end{array}$ & 1,350 male older adults & Sedentary behavior & $\begin{array}{l}\text { High levels of physical } \\
\text { activity }\end{array}$ & $\begin{array}{l}\text { High levels of physical } \\
\text { activity and low levels of } \\
\text { sedentary behavior, kidney } \\
\text { function }\end{array}$ \\
\hline $\begin{array}{l}\text { Bharakhada } \\
\text { et al. }{ }^{45)}(2012)\end{array}$ & England & $\begin{array}{l}\text { Cross-sectional } \\
\text { study }\end{array}$ & $\begin{array}{l}5,656 \text { for physical activity, } \\
6,281 \text { for sitting }\end{array}$ & $\begin{array}{l}\text { Mild physical activity, high } \\
\text { sitting time }\end{array}$ & $\begin{array}{l}\text { Moderate to intense physical } \\
\text { activity, low sitting time }\end{array}$ & $\begin{array}{c}\text { CKD: GFR }<60 \mathrm{~mL} / \mathrm{min} / 1.73 \\
\mathrm{~m}^{2} \text {, microalbuminuria }\end{array}$ \\
\hline $\begin{array}{l}\text { Pharr et al. }{ }^{40)} \\
(2018)\end{array}$ & Taiwan & $\begin{array}{l}\text { Cross-sectional } \\
\text { study }\end{array}$ & $\begin{array}{l}30,874 \text { women }(14,109 \\
\text { active/obese, } 16,765 \\
\text { inactive/normal weight) }\end{array}$ & $\begin{array}{l}\text { Inactive women/normal } \\
\text { weight }\end{array}$ & Active/obese women & $\begin{array}{l}\text { Active/obese women, } \\
\text { inactive/normal weight, } \\
\text { chronic diseases, chronic } \\
\text { kidney disease }\end{array}$ \\
\hline $\begin{array}{l}\text { Lee et al. }{ }^{411} \\
(2020)\end{array}$ & USA & $\begin{array}{l}\text { Cross-sectional } \\
\text { study }\end{array}$ & $\begin{array}{l}\text { 1,268 (586 men, } 682 \\
\text { women) }\end{array}$ & Sedentary time: $30 \mathrm{~min} / \mathrm{d}$ & $\begin{array}{l}\text { Moderate to intense physical } \\
\text { activity } 10 \mathrm{~min} / \mathrm{d}\end{array}$ & $\begin{array}{l}\text { CKD: GFR }<60 \mathrm{~mL} / \mathrm{min} / 1.73 \\
\mathrm{~m}^{2}, \text { albumin-creatinine } \\
\text { ratio }>25 / 35 \mu \mathrm{g} / \mathrm{mg} \text { (man/ } \\
\text { woman) }\end{array}$ \\
\hline
\end{tabular}

GFR, glomerular filtration rate; CKD, chronic kidney disease. 
2020); Taiwan (Su et al. ${ }^{42)}$ in 2015), Japan (Lee et al. ${ }^{43)}$ in 2016), United Kingdom (Parsons et al. ${ }^{44)}$ in 2017, Bharakhada et al. ${ }^{45}$ in 2012), and the Netherlands (Martens et al. ${ }^{46)}$ in 2018). The characteristics of the included studies are summarized in Table 1.

\section{The Methodological Quality of Individual Studies}

Of the eight articles selected for this systematic review, six were crosssectional, one cohort study, and one case-control study. The methodological quality of the studies within this systematic review is acceptable, generally with low risk of selection bias, confusion, and information, in the studies by Su et al., ${ }^{42)}$ Parsons et al., ${ }^{44)}$ Lee et al., ${ }^{43)}$ and Martens et al. ${ }^{46)}$ However, it should be noted that in a study of Pharr et al., ${ }^{40)}$ there was inadequate control for information bias and confounding, making its results unreliable and non-reproducible. In the study by Hawkins et al., ${ }^{39)}$ the methods for sample selection or the sequence of randomization of groups has not been described; thus, the risk of selection bias is unclear. In addition, the results, in general, were not comparable with each other due to the definitions of physical activity and sedentary lifestyle that each one used, since in some studies an accelerometer was used to measure the level of physical activity, while in others it was defined only by the report of the time of physical activity performed.

Likewise, the definition used for sedentary lifestyle was different in the studies, that of Martens et al. ${ }^{46)}$ quantified sedentary lifestyle in prolonged periods of rest, total sedentary time in hours per day, an average of minutes in prolonged periods of active rest, among others, making it difficult to identify the outcomes and the association measures for this study. In the studies by Lee et al. ${ }^{41)}$ and Bharakhada et al., ${ }^{45)}$ the data collection technique did not allow better control of possible information biases because self-filling surveys were used to capture mild, moderate, and intense physical activity, in addition to the sedentary or inactivity time, without carrying out objective measurements for these variables with the use of accelerometers as applied in other studies. Similarly, in a work of Lee et al., ${ }^{41)}$ the selection bias presented a considerable risk when taking inappropriate cut-off points in the level of physical activity of the participants to classify them into the different groups. The following Table 2 summarizes the risks of bias for each study.

\section{Individual Results of the Included Studies}

Most of the studies included in this systematic review agree that there was an association between a sedentary lifestyle and CKD; however, not all used the same definition of this disease, understood from the criteria established by the "Kidney Disease: Improving Global Outcomes $^{\prime \prime 4)}$ and in the same way, the definitions of physical activity and sedentary lifestyle were different between these studies. On the other hand, the method of collecting information was based on two main modalities: the survey was self-completed by the participants and the measurement of the variables under study. In the study by Hawkins et al., ${ }^{39)}$ the association measure obtained was a hazard ratio as it was a cohort type, and an OR was calculated for the other studies. Of the reviewed studies, the association between a sedentary lifestyle and CKD was found; $;^{39,41-46)}$ however, the study by Pharr et al. ${ }^{40)}$ did not show an association between a sedentary lifestyle and CKD (OR, 0.86; 95\% CI, 0.7-1.06), and the other studies showed that there was a non-causal association between a sedentary lifestyle and chronic kidney failure, despite multivariate models, which were adjusted for comorbidities known as proven risk factors for its onset, including arterial hypertension, diabetes mellitus, and CVD among others. In some studies, the exposure consisted of physical activity with OR indicating a possible protective factor, while in others, it was a sedentary lifestyle with OR indicating a risk factor in relation to chronic kidney failure. Given the disparities between the studies, comparison and statistical analysis to pool the effect into a summary measure were not possible. The results of each study are summarized in Table 3.

In the study by Martens et al., ${ }^{46)}$ the comparison was physical activity, quantified as total hours per day, intense physical activity $(>110$ steps/min every $10 \mathrm{~min} / \mathrm{d}$ ), and light physical activity ( $<110 \mathrm{steps} / \mathrm{min}$ for every $10 \mathrm{~min} / \mathrm{d}$ ) versus sedentary lifestyle, quantified as resting time in $\mathrm{h} / \mathrm{d}$, sedentary breaks at $10 \mathrm{~min} / \mathrm{d}$, and the number of prolonged periods of sedentary lifestyle per day. The outcome considered was microalbuminuria, categorized into three groups: $<15 \mathrm{mg} / 24 \mathrm{~h}$, $15-<30 \mathrm{mg} / 24 \mathrm{~h}$ and $>30 \mathrm{mg} / 24 \mathrm{~h}$. In a study of Lee et al., ${ }^{43)}$ the comparison was sitting: $<4 \mathrm{~h} / \mathrm{d}, 4-<6 \mathrm{~h} / \mathrm{d}$, and $>6 \mathrm{~h} / \mathrm{d}$, while the outcome was chronic renal failure defined as a GFR of $<60 \mathrm{~mL} / \mathrm{min} / 1.73 \mathrm{~m}^{2}$.

In the study by Parsons et al., ${ }^{44)}$ the level of physical activity was quantified as $<100$ counts/min (sedentary behavior), 100-1,040 counts/min (light activity), >1,040 counts/min (moderate to vigorous activity), and the outcome was GFR divided into $<45 \mathrm{~mL} / \mathrm{min} / 1.73 \mathrm{~m}^{2}$

Table 2. Risk of bias in included studies

\begin{tabular}{lcccc}
\hline \multicolumn{1}{c}{ Author (year) } & Selection bias risk & Information bias risk & Confusion bias risk & Methodological quality \\
\hline Hawkins et al. ${ }^{39)}(2015)$ & Uncertain & Low & Low & High \\
Su et al. ${ }^{42}(2015)$ & Low & Low & Low & High \\
Lee et al..$^{43)}(2016)$ & Low & Low & Low & High \\
Parsons et al..$^{44}(2017)$ & Low & Low & Low & High \\
Bharakhada et al..$^{55}(2012)$ & Low & Medium & Medium & Medium \\
Martens et al. ${ }^{46)}(2018)$ & Low & Low & Low & High \\
Pharr et al. ${ }^{40)}(2018)$ & Low & Medium & Medium & Medium \\
Lee et al..$^{41)}(2020)$ & Medium & Medium & Low & Medium \\
\hline
\end{tabular}


Table 3. Results of included studies

\begin{tabular}{|c|c|c|c|c|}
\hline Author (year) & Intervention/exposition & Comparison & Outcomes & Association measure \\
\hline $\begin{array}{l}\text { Hawkins et al. }{ }^{39)} \\
\text { (2015) }\end{array}$ & $\begin{array}{l}\text { Sedentary lifestyle: TV }<2 \mathrm{~h} / \mathrm{d} \text {, } \\
2-3 \mathrm{~h} / \mathrm{d},>3 \mathrm{~h} / \mathrm{d}\end{array}$ & $\begin{array}{l}\text { Physical activity: 0-48 kcal/kg/wk, } \\
48-93 \mathrm{kcal} / \mathrm{kg} / \mathrm{wk},>93 \mathrm{kcal} / \mathrm{kg} / \mathrm{wk}\end{array}$ & $\mathrm{GFR}<60 \mathrm{~mL} / \mathrm{min} / 1.73 \mathrm{~m}^{2}$ & $\mathrm{HR}, 1.34 ; 95 \% \mathrm{Cl}, 1.09-1.65$ \\
\hline Su et al. ${ }^{42)}(2015)$ & Physical activity: 3 times/wk & Physical activity: $<3$ times/wk & $\mathrm{GFR}<60 \mathrm{~mL} / \mathrm{min} / 1.73 \mathrm{~m}^{2}$ & $\mathrm{OR}, 0.74 ; 95 \% \mathrm{Cl}, 0.65-0.85$ \\
\hline $\begin{array}{l}\text { Lee et al. }{ }^{43)} \\
(2016)\end{array}$ & $\begin{array}{l}\text { Sitting: } 4-<6 \mathrm{~h} / \mathrm{d}, 6-<8 \mathrm{~h} / \mathrm{d}, \\
>8 \mathrm{~h} / \mathrm{d}\end{array}$ & Sitting: $<4 \mathrm{~h} / \mathrm{d}$ & Chronic kidney failure* & OR, $1.42^{+} ; 95 \% \mathrm{Cl}, 1.02-1.62$ \\
\hline $\begin{array}{l}\text { Parsons et al. }{ }^{44)} \\
(2017)\end{array}$ & $\begin{array}{l}\text { Sedentary behavior: }<100 \text { counts/ } \\
\text { min }\end{array}$ & $\begin{array}{l}100-1,040 \text { counts/min (light activity), } \\
>1,040 \text { counts/min (moderate to } \\
\text { vigorous activity) }\end{array}$ & $\begin{array}{l}<45 \mathrm{~mL} / \mathrm{min} / 1.73 \mathrm{~m}^{2},>45 \mathrm{~mL} \\
\min / 1.73 \mathrm{~m}^{2}\end{array}$ & $\mathrm{OR}, 1.16 ; 95 \% \mathrm{Cl}, 1.06-1.27$ \\
\hline $\begin{array}{l}\text { Bharakhada et } \\
\text { al. }{ }^{45)}(2012)\end{array}$ & $\begin{array}{l}\text { Mild physical activity, high sitting } \\
\text { time }\end{array}$ & $\begin{array}{l}\text { Moderate to intense physical activity, } \\
\text { low sitting time }\end{array}$ & $\begin{array}{l}\text { CKD: GFR }<60 \mathrm{~mL} / \mathrm{min} / 1.73 \mathrm{~m}^{2}, \\
\text { microalbuminuria }\end{array}$ & $\begin{array}{l}\text { Low sitting time: } \mathrm{OR}, 0.74 ; 95 \% \\
\mathrm{Cl}, 0.62-0.92 ; \text { intense } \\
\text { physical activity (men): } \mathrm{OR} \text {, } \\
0.63 ; 95 \% \mathrm{Cl}, 0.47-0.84\end{array}$ \\
\hline $\begin{array}{l}\text { Martens et al. }{ }^{46)} \\
\text { (2018) }\end{array}$ & $\begin{array}{l}\text { Sedentary time }(\mathrm{h} / \mathrm{d}) \text {, sedentary } \\
\text { breaks } 10 / \mathrm{d} \text {, number of long } \\
\text { sedentary periods/d }\end{array}$ & $\begin{array}{l}\text { Total physical activity }(\mathrm{h} / \mathrm{d}) \text {, intense } \\
\text { physical activity >110 steps/min for } \\
10 \mathrm{~min} / \mathrm{d} \text {, light physical activity } \\
\leq 110 \mathrm{steps} / \mathrm{min} \text { for } 10 \mathrm{~min} / \mathrm{d}\end{array}$ & Microalbuminuria >30 mg/24 h & $\begin{array}{l}\mathrm{OR}, 1.11 ; 95 \% \mathrm{Cl}, 1.01-1.24 \\
\mathrm{OR}, 1.11 ; 95 \% \mathrm{Cl}, 11.01- \\
1.23\end{array}$ \\
\hline $\begin{array}{l}\text { Pharr et al. }{ }^{40)} \\
(2018)\end{array}$ & $\begin{array}{l}\text { 11-149 min/wk of aerobic activity } \\
\text { (insufficient activity), no aerobic } \\
\text { activity (inactivity) }\end{array}$ & $\begin{array}{l}300 \text { min of aerobic activity or } 150 \\
\text { min/wk of vigorous aerobic exercise } \\
\text { (high activity), } 150-300 \text { min/wk of } \\
\text { aerobic activity (moderate activity) }\end{array}$ & Chronic kidney failure* & $\mathrm{OR}, 0.86 ; 95 \% \mathrm{Cl}, 0.65-0.85$ \\
\hline $\begin{array}{l}\text { Lee et al. }{ }^{41)} \\
(2020)\end{array}$ & Sedentary time: $30 \mathrm{~min} / \mathrm{d}$ & $\begin{array}{l}\text { Moderate to intense physical activity: } \\
10 \mathrm{~min} / \mathrm{d}\end{array}$ & $\begin{array}{l}\text { CKD: GFR }<60 \mathrm{~mL} / \mathrm{min} / 1.73 \mathrm{~m}^{2}, \\
\text { albumin-creatinine ratio }>25 / 35 \\
\mu \mathrm{g} / \mathrm{mg} \text { (man/woman) }\end{array}$ & $\begin{array}{l}\text { Total physical activity: OR, 0.86; } \\
95 \% \mathrm{Cl}, 0.78-0.96 ; \text { mild } \\
\text { physical activity: OR, 0.87; } \\
95 \% \mathrm{Cl}, 0.76-0.99 ; \text { sedentary } \\
\text { time for every } 30 \mathrm{~min} / \mathrm{d} \text { : OR, } \\
1.16 ; 95 \% \mathrm{Cl}, 1.04-1.29\end{array}$ \\
\hline
\end{tabular}

GFR, glomerular filtration rate; $\mathrm{HR}$, hazard ratio; $\mathrm{Cl}$, confidence interval; OR, odds ratio; CKD, chronic kidney disease.

${ }^{*}$ Chronic renal failure as a function of GFR is not defined. 'Daily sitting between 6-8 hours had an OR of $1.24(95 \% \mathrm{Cl}, 1.06-1.43)$.

and $45 \mathrm{~mL} / \mathrm{min} / 1.73 \mathrm{~m}^{2}$ or higher.

In the study by Pharr, et al. ${ }^{40)}$ physical activity was measured as high activity (300 minutes of aerobic activity or $150 \mathrm{~min} / \mathrm{wk}$ of vigorous aerobic exercise), moderate activity (150-300 min/wk of aerobic activity), insufficient activity (11-149 min/wk of aerobic activity), and inactivity, while the outcome was $\mathrm{CKD}$, which was not clearly defined by the study.

In addition, the studies by Hawkins et al..$^{39)}$ and Su et al. ${ }^{42)}$ measured physical activity based on calorie consumption, dividing it into three categories: 0-48 kcal/kg/wk, 48-93 kcal/kg/wk, and >93 kcal/kg/wk; ${ }^{39}$ the absence or presence of physical activity: physical activity, 3 times/ wk (yes), activity <3 times/wk (no); ${ }^{42)}$ and sedentary lifestyle as time watching television (TV), $<2 \mathrm{~h} / \mathrm{d}, 2-3 \mathrm{~h} / \mathrm{d}$, and $>3 \mathrm{~h} / \mathrm{d}{ }^{39)}$ The outcome for both was CKD as a GFR of $<60 \mathrm{~mL} / \mathrm{min} / 1.73 \mathrm{~m}^{2}$.

In the studies by Bharakhada et al. ${ }^{45)}$ and Lee et al., ${ }^{41)}$ low sitting or sedentary time and moderate to intense physical activity showed a possible relationship as protective factors against chronic kidney failure, while sitting for a long time and less physical activity were possible risk factors for this outcome. We found that the reviewed studies adjusted for potentially confusing variables, such as hypertension or diabetes mellitus, as well as for age, body mass index, and neoplasms, among others, the association between sedentary lifestyle/physical activity and chronic kidney failure was lost in the multivariate study analysis, as occurred in the work of Parsons et al., ${ }^{44)}$ and Pharr et al., ${ }^{40)}$ (OR, 1.05; 95\% CI, 0.93-1.05; OR, 0.94; 95\% CI, 0.73-1.21).

\section{DISCUSSION}

According to the majority of studies that were reviewed, in CKD, it can be considered that there was an association between a sedentary lifestyle and its appearance in people without other comorbidities. However, the strength of this association is not robust because the level of evidence of the studies was not the highest, since only one cohort study could be included ${ }^{39)}$ as the one with the highest level of evidence compared to the cross-sectional and case-control studies. ${ }^{40-46)}$ In addition, these studies evaluated multiple causal factors for other outcomes, such as arterial hypertension, diabetes mellitus, and coronary disease, the presence of which is a known risk factor for the appearance of CKD, although the authors of these studies were cautious when performing subgroup analyses and attempted to adjust for these risk factors to avoid confounding bias.

Cross-sectional studies do not analyze the association of a risk factor with an outcome over time, a longitudinal analysis cannot be made, and neither do they look at whether the different degrees of exposure to a risk factor that cause it to increase. Previous studies demonstrating the association between physical activity and CKD have been mainly cross-sectional, raising concerns about reverse causality. ${ }^{48-50)}$

Unfortunately, many of the studies investigating the relationship between physical activity and CKD have relied on subjective measures and memories (interviews and questionnaires) to document physical activity ${ }^{28,48)}$ Although these and other studies have consistently shown 
that kidney function is significantly associated with self-reported levels of physical activity, difficulties persist not only in quantifying vigorous exercise training, but even more so in capturing both intentional and unintended movements at lower intensities, ${ }^{51,52)}$ and in the measurement of sedentary behavior. ${ }^{53)}$ Since participation in physical activity without exercise might be the main source of muscular effort for many, if not most, it cannot be ignored when assessing cardiorenal and metabolic risk. ${ }^{52,53)}$

Unlike our study, Volaklis et al. ${ }^{54)}$ conducted a narrative review of sedentary behavior and renal function in adults and evaluated a total of 10 articles between cross-sectional and longitudinal observational studies that included healthy participants and groups of patients, in which they summarized the cross-sectional and longitudinal relationship between a sedentary lifestyle and kidney function estimated using GFR. These results suggest that a sedentary lifestyle is a risk factor for kidney failure. These findings are clinically relevant since a sedentary lifestyle is modifiable, and this might be particularly important for older people because kidney function declines with age.

Most people spent more than half of their waking hours engaging in light physical activity and sedentary behavior. As a result, and in accordance with the growing scientific evidence presented in this review, prolonged sitting time appears to have detrimental consequences for normal kidney function.

The results of both studies are similar; however, in the study by Volaklis et al., ${ }^{54)}$ all patients with different characteristics were considered, both healthy and those with some comorbidity, which could change the magnitude of the association and not determine whether physical activity benefits more patients who are previously healthy or who have some comorbidities, such as hypertension, diabetes mellitus, and CVD.

\section{Conclusion}

It was not possible to calculate the summary measure using metaanalysis because the measure of association of the studies was not comparable, due to the lack of uniformity in the definition of the interventions, the comparisons, and outcome of interest, in addition to studying different populations whose characteristics do not allow the extrapolation and generalization of the results found in each publication reviewed here. For this reason, the execution of studies that have a higher level of evidence and a better-structured protocol is pending to make it possible to compare them and obtain a summary measure using the meta-analysis technique.

The use of subjective self-reported questionnaires for the assessment of sedentary behavior might be subject to bias; therefore, more studies with measurements derived from precision devices, such as accelerometers, are required.

Despite the vast amount of scientific content on the relationship that may exist between sedentary lifestyle, whether in healthy people or not, and the development of CKD, there is evidence that there is a need to further distinguish between sedentary time by visualization of television and occupational sedentary lifestyle, to define exactly the health risks conferred by sedentary behavior, such as television viewing time that appears to be more detrimental with respect to health outcomes. These studies on the different types of sedentary time and the risk of renal dysfunction have not been reported in the study. ${ }^{55,56)}$

At the population level, it is necessary to understand and identify the environmental, social, and personal determinants of sedentary behavior and to investigate whether a sedentary lifestyle is equally relevant in healthy and physically active people, as in physically inactive participants with or without disease.

By working on modifiable risk factors in different population groups and, above all, in childhood and adolescence, the level of sedentary lifestyle can be improved, which could lead to a reduction in the risk of developing chronic diseases such as kidney disease. Since no definitive studies were found, it is suggested that more specific research should be conducted regarding factors associated with CKD.

\section{Study Limitations}

There is little quality scientific evidence and homogenization; thus, more observational and interventional studies are needed, in which the same measurements are used for a sedentary lifestyle and physical inactivity, if possible, they are applied in different age and population groups, in order to measure the magnitude and association of these risk factors to trigger $\mathrm{CKD}$.

\section{CONFLICT OF INTEREST}

No potential conflict of interest relevant to this article was reported.

\section{ACKNOWLEDGMENTS}

I want to thank my family first, who has supported me over the years to achieve the result of this work. I also want to thank my teachers, who were my mentors and guides along this path.

\section{ORCID}

Alejandro Tavera Concha: https://orcid.org/0000-0003-3629-2431

Franklin Alejandro Rico Mendoza: https://orcid.org/0000-0002-4291-6135

\section{REFERENCES}

1. Pan American Health Organization. PAHO/WHO and the Latin American Society of Nephrology call to prevent kidney disease and improve access to treatment [Internet]. Washington (DC): Pan American Health Organization; 2015 [cited 2018 Jul 23]. Available from: https:// www.paho.org/hq/index.php?option=com_content\&review= article\&i-d=10542\%3A2015-opsoms-sociedad-latinoamericananefrologia-enfermedad-renal-mejorar-tratamiento\&catid $=740 \%$ 3Apress-releases\&Itemid=1926\&lang=pt.

2. Stanifer JW, Muiru A, Jafar TH, Patel UD. Chronic kidney disease in low- and middle-income countries. Nephrol Dial Transplant 2016;31: 868-74. 
3. Mills KT, Xu Y, Zhang W, Bundy JD, Chen CS, Kelly TN, et al. A systematic analysis of worldwide population-based data on the global burden of chronic kidney disease in 2010. Kidney Int 2015;88:950-7.

4. Jha V, Garcia-Garcia G, Iseki K, Li Z, Naicker S, Plattner B, et al. Chronic kidney disease: global dimension and perspectives. Lancet 2013;382: 260-72.

5. GBD 2013 Mortality and Causes of Death Collaborators. Global, regional, and national age-sex specific all-cause and cause-specific mortality for 240 causes of death, 1990-2013: a systematic analysis for the Global Burden of Disease Study 2013. Lancet 2015;385:117-71.

6. Cuenta de Alto Costo. Situation of chronic kidney disease, high blood pressure and diabetes mellitus in Colombia 2018. Bogota: High-Cost Account (Cuenta de Alto Costo); 2019.

7. Ministry of Health and Social Protection of Colombia. Clinical practice guide for the diagnosis and treatment of chronic kidney disease. Bogota: Institute for Health Technology Assessment; 2016.

8. Healy GN, Wijndaele K, Dunstan DW, Shaw JE, Salmon J, Zimmet PZ, et al. Objectively measured sedentary time, physical activity, and metabolic risk: the Australian Diabetes, Obesity and Lifestyle Study (AusDiab). Diabetes Care 2008;31:369-71.

9. Stump CS. Physical activity in the prevention of chronic kidney disease. Cardiorenal Med 2011;1:164-73.

10. Linke A, Erbs S, Hambrecht R. Effects of exercise training upon endothelial function in patients with cardiovascular disease. Front Biosci 2008;13:424-32.

11. Wisse BE. The inflammatory syndrome: the role of adipose tissue cytokines in metabolic disorders linked to obesity. J Am Soc Nephrol 2004;15:2792-800.

12. Thorp AA, Healy GN, Owen N, Salmon J, Ball K, Shaw JE, et al. Deleterious associations of sitting time and television viewing time with cardiometabolic risk biomarkers: Australian Diabetes, Obesity and Lifestyle (AusDiab) study 2004-2005. Diabetes Care 2010;33:327-34.

13. Dunstan DW, Salmon J, Owen N, Armstrong T, Zimmet PZ, Welborn $\mathrm{TA}$, et al. Associations of TV viewing and physical activity with the metabolic syndrome in Australian adults. Diabetologia 2005;48:225461.

14. Dunstan DW, Salmon J, Owen N, Armstrong T, Zimmet PZ, Welborn TA, et al. Physical activity and television viewing in relation to risk of undiagnosed abnormal glucose metabolism in adults. Diabetes Care 2004;27:2603-9.

15. Katzmarzyk PT, Church TS, Craig CL, Bouchard C. Sitting time and mortality from all causes, cardiovascular disease, and cancer. Med Sci Sports Exerc 2009;41:998-1005.

16. Dunstan DW, Barr EL, Healy GN, Salmon J, Shaw JE, Balkau B, et al. Television viewing time and mortality: the Australian Diabetes, Obesity and Lifestyle Study (AusDiab). Circulation 2010;121:384-91.

17. Wijndaele K, Brage S, Besson H, Khaw KT, Sharp SJ, Luben R, et al. Television viewing time independently predicts all-cause and cardiovascular mortality: the EPIC Norfolk study. Int J Epidemiol 2011;40: $150-9$.

18. Pickup JC, Crook MA. Is type II diabetes mellitus a disease of the innate immune system? Diabetologia 1998;41:1241-8.

19. Tataranni PA, Ortega E. A burning question: does an adipokine-induced activation of the immune system mediate the effect of overnutrition on type 2 diabetes? Diabetes 2005;54:917-27.
20. Lago R, Gomez R, Lago F, Gomez-Reino J, Gualillo O. Leptin beyond body weight regulation: current concepts concerning its role in immune function and inflammation. Cell Immunol 2008;252:139-45.

21. Franks PW, Farooqi IS, Luan J, Wong MY, Halsall I, O'Rahilly S, et al. Does physical activity energy expenditure explain the between-individual variation in plasma leptin concentrations after adjusting for differences in body composition? J Clin Endocrinol Metab 2003;88:325863.

22. Panagiotakos DB, Pitsavos C, Chrysohoou C, Kavouras S, Stefanadis C; ATTICA Study. The associations between leisure-time physical activity and inflammatory and coagulation markers related to cardiovascular disease: the ATTICA Study. Prev Med 2005;40:432-7.

23. Herder C, Peltonen M, Koenig W, Sutfels K, Lindstrom J, Martin S, et al. Anti-inflammatory effect of lifestyle changes in the Finnish Diabetes Prevention Study. Diabetologia 2009;52:433-42.

24. Kasapis C, Thompson PD. The effects of physical activity on serum Creactive protein and inflammatory markers: a systematic review. J Am Coll Cardiol 2005;45:1563-9.

25. Yates T, Khunti K, Wilmot EG, Brady E, Webb D, Srinivasan B, et al. Self-reported sitting time and markers of inflammation, insulin resistance, and adiposity. Am J Prev Med 2012;42:1-7.

26. Beddhu S. Sit less, interact, move more (SLIMM) intervention for sedentary behavior in chronic kidney disease (CKD) (SLIMM): NCT02970123. Bethesda (MD): National Library of Medicine, ClinicalTrials.gov; 2016.

27. World Health Organization. Global recommendations on physical activity for health. Geneva: World Health Organization; 2010.

28. Robinson-Cohen C, Katz R, Mozaffarian D, Dalrymple LS, de Boer I, Sarnak M, et al. Physical activity and rapid decline in kidney function among older adults. Arch Intern Med 2009;169:2116-23.

29. Tufanaru C, Munn Z, Aromataris E, Campbell J, Hopp L. Chapter 3: systematic reviews of effectiveness. In: Aromataris E, Munn Z, editors. JBI manual for evidence synthesis. North Adelaide: The Joanna Briggs Institute; 2017.

30. Moher D, Shamseer L, Clarke M, Ghersi D, Liberati A, Petticrew M, et al. Preferred reporting items for systematic review and meta-analysis protocols (PRISMA-P) 2015 statement. Syst Rev 2015;4:1.

31. Taylor HL, Jacobs DR Jr, Schucker B, Knudsen J, Leon AS, Debacker G. A questionnaire for the assessment of leisure time physical activities. J Chronic Dis 1978;31:741-55.

32. Brach JS, Simonsick EM, Kritchevsky S, Yaffe K, Newman AB; Health, Aging and Body Composition Study Research Group. The association between physical function and lifestyle activity and exercise in the health, aging and body composition study. J Am Geriatr Soc 2004;52:502-9.

33. Topolski TD, LoGerfo J, Patrick DL, Williams B, Walwick J, Patrick MB. The Rapid Assessment of Physical Activity (RAPA) among older adults. Prev Chronic Dis 2006;3:A118.

34. Ainsworth BE, Haskell WL, Whitt MC, Irwin ML, Swartz AM, Strath SJ, et al. Compendium of physical activities: an update of activity codes and MET intensities. Med Sci Sports Exerc 2000;32(9 Suppl):S498-504.

35. The Joanna Briggs Institute. The Joanna Briggs Institute Critical Appraisal tools for use in JBI systematic reviews: checklist for analytical cross sectional studies. North Adelaide: The Joanna Briggs Institute; 2017.

36. Porritt K, Gomersall J, Lockwood C. JBI's systematic reviews: study se- 
lection and critical appraisal. Am J Nurs 2014;114:47-52.

37. Munn Z, Tufanaru C, Aromataris E. JBI's systematic reviews: data extraction and synthesis. Am J Nurs 2014;114:49-54.

38. GRADEpro GDT. GRADEpro Guideline Development Tool [software]. Hamilton (ON): McMaster University; 2015.

39. Hawkins M, Newman AB, Madero M, Patel KV, Shlipak MG, Cooper J, et al. TV watching, but not physical activity, is associated with change in kidney function in older adults. J Phys Act Health 2015;12:561-8.

40. Pharr JR, Coughenour CA, Bungum TJ. An assessment of the relationship of physical activity, obesity, and chronic diseases/conditions between active/obese and sedentary/normal weight American women in a national sample. Public Health 2018;156:117-23.

41. Lee J, Walker ME, Gabriel KP, Vasan RS, Xanthakis V. Associations of accelerometer-measured physical activity and sedentary time with chronic kidney disease: the Framingham Heart Study. PLoS One 2020;15:e0234825.

42. Su SL, Lin C, Kao S, Wu CC, Lu KC, Lai CH, et al. Risk factors and their interaction on chronic kidney disease: a multi-centre case control study in Taiwan. BMC Nephrol 2015;16:83.

43. Lee S, Shimada H, Lee S, Makizako H, Doi T, Harada K, et al. Association between sedentary time and kidney function in communitydwelling elderly Japanese people. Geriatr Gerontol Int 2017;17:730-6.

44. Parsons TJ, Sartini C, Ash S, Lennon LT, Wannamethee SG, Lee IM, et al. Objectively measured physical activity and kidney function in older men; a cross-sectional population-based study. Age Ageing 2017;46: 1010-4.

45. Bharakhada N, Yates T, Davies MJ, Wilmot EG, Edwardson C, Henson J, et al. Association of sitting time and physical activity with CKD: a cross-sectional study in family practices. Am J Kidney Dis 2012;60:58390.

46. Martens RJ, van der Berg JD, Stehouwer CD, Henry RM, Bosma H, Dagnelie PC, et al. Amount and pattern of physical activity and sedentary behavior are associated with kidney function and kidney damage: the Maastricht Study. PLoS One 2018;13:e0195306.

47. Chapter 1: Definition and classification of CKD. Kidney Int Suppl (2011) 2013;3:19-62.

48. Finkelstein J, Joshi A, Hise MK. Association of physical activity and renal function in subjects with and without metabolic syndrome: a review of the Third National Health and Nutrition Examination Survey (NHANES III). Am J Kidney Dis 2006;48:372-82.

49. Kurella M, Ireland C, Hlatky MA, Shlipak MG, Yaffe K, Hulley SB, et al. Physical and sexual function in women with chronic kidney disease. Am J Kidney Dis 2004;43:868-76.

50. Hallan S, de Mutsert R, Carlsen S, Dekker FW, Aasarod K, Holmen J. Obesity, smoking, and physical inactivity as risk factors for CKD: are men more vulnerable? Am J Kidney Dis 2006;47:396-405.

51. Levine JA. Nonexercise activity thermogenesis (NEAT): environment and biology. Am J Physiol Endocrinol Metab 2004;286:E675-85.

52. Thompson D, Batterham AM, Bock S, Robson C, Stokes K. Assessment of low-to-moderate intensity physical activity thermogenesis in young adults using synchronized heart rate and accelerometry with branched-equation modeling. J Nutr 2006;136:1037-42.

53. Hart TL, Ainsworth BE, Tudor-Locke C. Objective and subjective measures of sedentary behavior and physical activity. Med Sci Sports Exerc 2011;43:449-56.

54. Volaklis K, Mamadjanov T, Meisinger C. Sedentary behavior and kidney function in adults: a narrative review. Wien Klin Wochenschr 2021;133:144-52.

55. Garcia JM, Duran AT, Schwartz JE, Booth JN 3rd, Hooker SP, Willey JZ, et al. Types of sedentary behavior and risk of cardiovascular events and mortality in blacks: the Jackson Heart Study. J Am Heart Assoc 2019;8:e010406.

56. Ciccone J, Woodruff SJ, Fryer K, Campbell T, Cole M. Associations among evening snacking, screen time, weight status, and overall diet quality in young adolescents. Appl Physiol Nutr Metab 2013;38:789-94. 


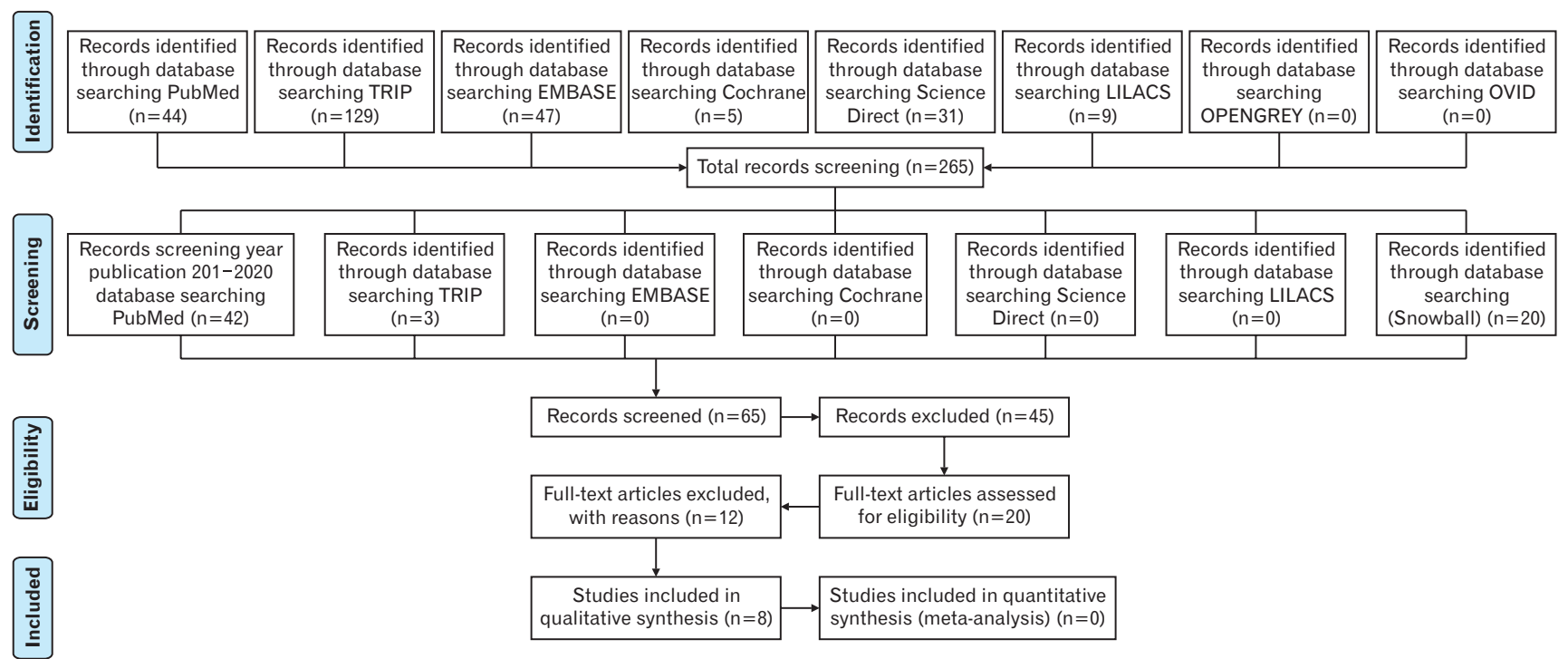

Appendix 1. PRISMA (Preferred Reporting Items for Systematic reviews and Meta-Analyses) flow diagram. 